\title{
Ovarian Yolk Sac Tumor, Glandular Pattern
}

National Cancer Institute

\section{Source}

National Cancer Institute. Ovarian Yolk Sac Tumor, Glandular Pattern. NCI Thesaurus.

Code C39988.

A yolk sac tumor that arises from the ovary and is characterized by the presence of extensive differentiation into endodermal type glandular structures. 